\title{
La reactivación de los programas embrionarios en las patologías del adulto
}

\author{
M. Ángela Nieto \\ Instituto de Neurociencias CSIC-UMH
}

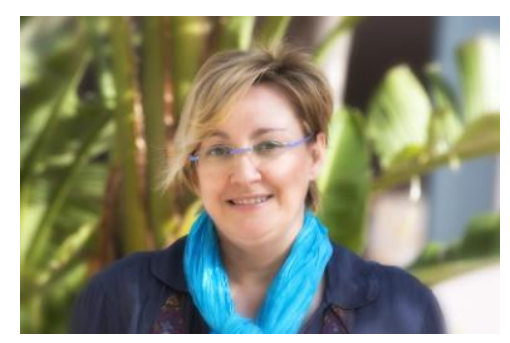

\section{Biografía Resumen}

Angela Nieto se doctoró por la Universidad Autónoma de Madrid en 1987 y tras una estancia en el Instituto de Investigaciones Biomédicas Alberto Sols (CSIC-UAM), se trasladó al National Institute for Medical Research, en Londres.

En 1993 regresó a España al Instituto Cajal (CSIC) de Madrid

y en 2004 se trasladó con su grupo al Instituto de Neurociencias (CSIC-UMH) en Alicante donde es Profesora de Investigación y directora de la

Unidad de Neurobiología del Desarrollo. Su principal contribución ha sido el aislamiento y caracterización de la familia génica Snail, mostrando su papel en la formación de tejidos embrionarios y cómo su reactivación en el adulto da lugar a distintas patologías, incluyendo la progresión del cáncer, la fibrosis y defectos en el crecimiento y la mineralización de los huesos.

Es miembro de $E M B O$, de la Academia Europea y de varios comités científicos y editoriales internacionales. Ha recibido los

Premios de las Fundaciones Carmen y Severo Ochoa (2004), Francisco Cobos (2005) y Alberto Sols (2006) y el Premio Rey Jaime I (2009).

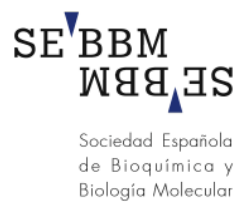

La activación aberrante de procesos del desarrollo embrionario en el adulto da lugar a distintas patologías. Un ejemplo paradigmático lo constituyen los genes Snail, necesarios para la formación de numerosos tejidos embrionarios e iniciadores de la progresión tumoral hacia la metástasis y de la aparición de fibrosis y de patologías óseas.

\section{Summary}

The aberrant reactivation of developmental programmes leads to the generation of several adult pathologies. Snail transcription factors are a paradigmatic example, as they are crucial for the development of multiple tissues in the embryo while they can initiate the metastatic cascade in tumours and the development of organ fibrosis and bone pathologies in the adult.

http://www.sebbm.es/

HEMEROTECA:

http://www.sebbm.es/ES/divulgacion-ciencia-para-todos_10/acercate-a-nuestros-cientificos_107

Snail en el desarrollo embrionario:

La cresta neural y el mesodermo- Durante el desarrollo hay mutitud de tejidos cuya formación implica la migración de células desde su lugar de origen hasta su destino final. El mesodermo y la cresta neural son ejemplos muy relevantes, ya que son los precursores del sistema nervioso periférico, las células pigmentadas y el esqueleto craneofacial por un lado, y los músculos, los huesos del tronco y las extremidades y componentes de la dermis por otro (1). El mesodermo se origina en la llamada línea primitiva y la cresta neural en la parte dorsal del tubo neural tras un proceso denominado transición epitelio-meséquima (EMT) por el que las células adquieren la capacidad de moverse y migrar a través de la matriz extracelular.

El proceso de EMT está regulado por una conjunción de factores entre los que destacan los miembros de la familia Snail, factores de transcripción del tipo "dedos de zinc" (2). Las mutaciones que anulan la función de Snail son letales en estadios embrionarios tempranos pues su falta impide la migración de las células mesodérmicas desde la línea primitiva (3).

Snail en la investigación Biomédica: Progresión tumoral, fibrosis y patologías óseas:

Una vez ejercida su función, Snail debe apagarse ya que su activación aberrante da lugar a varias patologías. Este "alter ego" de Snail no implica cambios en la proteína, sino su hiperactivación o su activación en lugares que no le corresponde.

Progresión Tumoral- El reconocimiento de la EMT como el primer paso del proceso metastásico, es decir, la delaminación de las células malignas del tumor primario, se ha cuestionado durante años. Hasta recientemente no había sido posible identificar los signos de EMT en tumores de pacientes debido a que en muchos casos es un fenómeno focal y a que las células que han sufrido la EMT son muy difíciles de distinguir de otras células presentes en el estroma tumoral. La obtención de imágenes de la masa tumoral in vivo en ratones ha permitido establecer que el tumor sufre un proceso de EMT semejante al que ocurría en los embriones para adquirir la capacidad de invadir otros tejidos y órganos (4). Se conoce que Snail1 se activa en los frentes de invasión de 
tumores tanto inducidos experimentalmente como en muestras obtenidas de pacientes con tumores de distintas etiologías (5), considerándose un marcador precoz de malignidad tumoral y una diana para terapias antiinvasivas y anti-metastásicas.

Fibrosis- Snail es importante durante el desarrollo del sistema renal, pero una vez diferenciados los túbulos renales y los ductos colectores debe mantenerse silente. Este silenciamiento es importante porque su simple activación en el riñón adulto conduce a una EMT que conlleva la desaparición de los túbulos renales y el desarrollo de la fibrosis y muerte por fallo renal (6). La reaparición de Snail en estos procesos de degeneración orgánica puede interpretarse de nuevo como la reactivación de programas embrionarios en un intento de recuperación del tejido que se torna letal.

Patologías óseas- Snail se expresa de forma normal durante el desarrollo de los huesos, donde trasmite la señal del receptor 3 del factor de crecimiento fibroblástico (FGFR3). La intensidad de esta señal controla la longitud de los huesos largos de tal forma que a mayor actividad antes se bloquea el crecimiento. Así, cuando una mutación en el receptor aumenta su actividad de forma descontrolada o se produce una activación aberrante de Snail aparece la acondroplasia, la forma más común de enanismo genético en humanos (7). Además, el silenciamiento de Snail incluso anula la actividad del FGFR3 mutado que genera el fenotipo acondroplásico. Por lo tanto, si fuera posible controlar la actividad de Snail podría controlarse la longitud de los huesos largos (8).

La integridad ósea en el adulto depende del balance entre la formación y la destrucción de hueso que debe mantenerse en homesotasis. Estos procesos están gobernados por células especializadas que producen hueso, los osteoblastos, y células que lo destruyen, los osteoclastos. La actividad de Snail, como en los condrocitos, es necesaria en el momento del inicio de la diferenciación de los osteoblastos que tiene lugar durante toda la vida. Si la expresión de Snail se escapa del control estricto espacio-temporal a que está sometida se generan osteoblastos inmaduros, incapaces de calcificar de la matriz ósea dando lugar a defectos de la mineralización, enfermedad conocida como osteomalacia (9).

Snail y la EMT como nodo central de múltiples procesos en la salud y la enfermedad:

Snail y la EMT se han revelado como nodos centrales en multitud de procesos fisiológicos y patológicos. Además de su papel en la generación de órganos y de su implicación en la progresión tumoral y la fibrosis, la EMT también ha propocionado una explicación para las conocidas asociaciones entre estas patologías y la inflamación y entre la progresión del cáncer y la immunosupresión. Además, también se ha relacionado a la EMT con la adquisición de propiedades de células madre, abriendo nuevos caminos para el desarrollo de terapias especificas para revertir el fenotipo mesenquimático al fenotipo epitelial, disminuir la inflamación y restaurar la inmunocompetencia (5; Fig. 1).

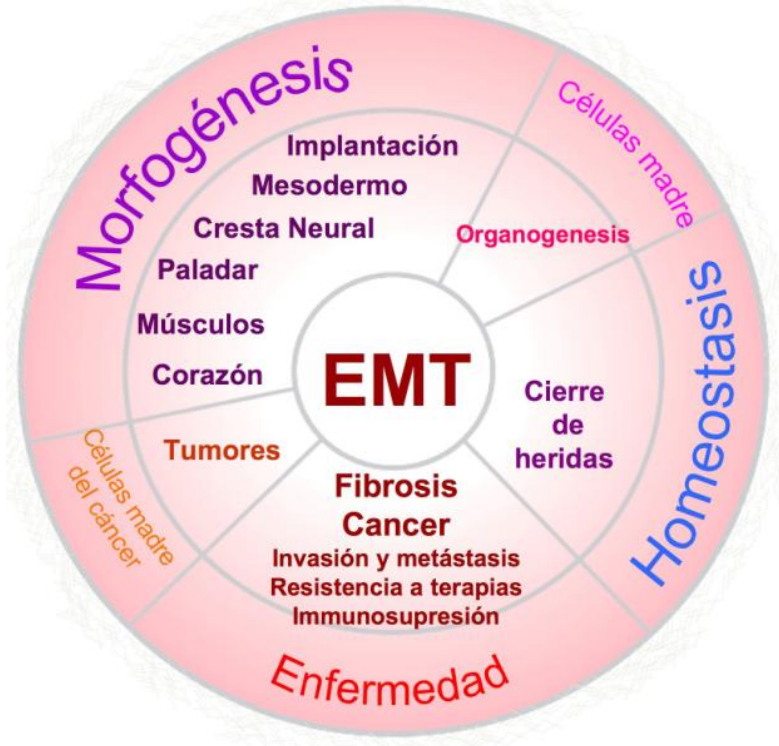

Figura- La EMT en el cruce de caminos de la salud y la enfermedad. Adaptado de (5).

Referencias

1. Gilbert S. Developmental Biology. 8th Edition. 2006. Sinauer Assoc. Sunderland, MA, USA.

2. Peinado $H$, Olmeda $D$ and Cano A. Snail, Zeb and bHLH factors in tumour progression: an alliance against the epithelial phenotype? Nature Rev Cancer, 2007; 7:415-428.

3. Nieto, M. A. The Snail superfamily of zinc finger transcription factors. Nature Rev. Mol. Cell Biol., 2002; 3: 155-166.

4. Wyckoff, J.B., y cols. Direct visualization of macrophage-assisted tumor cell intravasation in mammary tumors. Cancer Res., 2007; 67: 2649-2656.

5. Thiery, J.P., Acloque, H., Huang, R.Y. and Nieto, M.A. Epithelial-mesenchymal transitions in development and disease: the remarkable plasticity of the mesenchymal state. Cell, 2009, 139: 871-890.

6. Boutet, A., y cols. Snail activation disrupts tissue homeostasis and induces fibrosis in the adult kidney. EMBO J., 2006; 25: 5603-5613.

7. Horton, W.A. Recent milestones in achondroplasia research. Am J Med Genet., 2006; 140: 166-169.

8. De Frutos, C.A., y cols. Snail is a transcriptional effector of FGFR3 signaling during chondrogenesis and achondroplasias. Dev. Cell, 2007; 13: 872-883.

9. De Frutos, C.A., y cols. Snail 1 controls bone mass by regulating Runx2 and VDR expression during osteoblast differentiation. EMBO J., 2009; 28: 686-696. 